\title{
Rejoining the planning and public health fields: Leveraging comprehensive plans to strengthen food systems in an urban versus nural jurisdiction
}

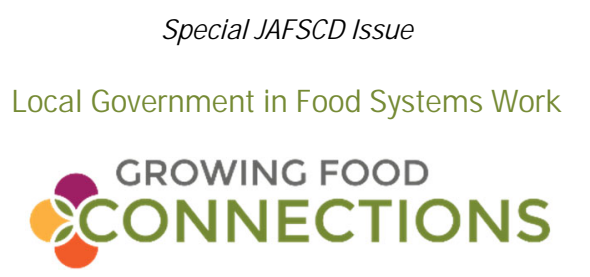

Special JAFSCD Issue

Local Government in Food Systems Work

CONNECTIONS

\author{
Yeeli Muia* \\ University at Buffalo, State University of New Y ork \\ Maryam Khojasteh ${ }^{\mathrm{b}}$ \\ University of Pennsylvania \\ Kimberley Hodgson ${ }^{c}$ \\ Cultivating Healthy Places \\ Samina Raja ${ }^{\mathrm{d}}$ \\ University at Buffalo, State University of New Y ork
}

Submitted January 19, 2018 / Revised April 6 and May 2, 2018 / Accepted May 2, 2018 /

Published online O ctober 17, 2018

Citation: Mui, Y., Khojasteh, M., Hodgson, K., \& Raja, S. (2018). Rejoining the planning and public health fields: Leveraging comprehensive plans to strength food systems in an urban versus rural jurisdiction. Journal of A griculture, Food Systems, and C ommunity D evelopment, 8(Suppl. 2), 73-93. https:/ / doi.org/ 10.5304/ jafscd.2018.08B.004

Copyright (C) 2018 by the Authors. Published by the Lyson Center for Civic Agriculture and Food Systems. Open access under CC BY license.

\begin{abstract}
The growth of health disparities in the United States, particularly those associated with dietrelated diseases, has motivated a reconvergence of

a* Corresponding author: Y eeli Mui, D epartment of Urban and Regional Planning, State University of New Y ork at Buffalo; 233B Hayes Hall; Buffalo, NY 14214 USA; +1-716-829-3782; yeelimui@buffalo.edu

b Maryam Khojasteh, City and Regional Planning, University of Pennsylvania; Meyerson Hall, 210 South 34th Street; Philadelphia, PA 19104 USA; maryamkh@ design.upenn.edu

c Kimberley Hodgson; Cultivating Healthy Places; Vancouver, BC, Canada; kim@ chplaces.com

d Samina Raja, D epartment of Urban and Regional Planning, State University of New Y ork at Buffalo; 233C Hayes Hall; Buffalo, NY 14214 USA; +1-716-829-5881; sraja@ buffalo.edu
\end{abstract}

the public health and planning disciplines to address this shared challenge. However, the dynamics and mechanisms through which public health and planning agencies can systematically address food-related issues have yet to be fully understood. This study analyzes how partnership between public health professionals and planners in local, regional, and metropolitan (LRM) governments can strengthen community food systems through a more integrated and holistic approach to health. Using a national survey of

\section{Funding Disclosure}

This research was made possible through a grant from the National Institute of Food and Agriculture Grant \# 201268004-19894, University at Buffalo Food Systems Planning and Healthy Communities Lab, and University at Buffalo Community of Global Health Equity (UB CGHE). 
planning practitioners, we identify which formal local government plans are more likely to address food-related issues, as a way to offer insights on where engagement with public health agencies could be leveraged. O ur analysis is further complemented by conducting semistructured interviews with LRM governments in two communities that are known for their innovative plans and policies, to explore how this crossdisciplinary relationship unfolds on the ground. Findings reveal that comprehensive plans are most likely to address the food system, while stand-alone food systems plans are the least common formal plan to be adopted by LRM governments. Stakeholder interviews highlight how the planningpublic health partnership can leverage local assets and strengthen the food system in urban versus rural jurisdictions, by formalizing cross-collaboration, identifying shared objectives, and building capacity.

\section{Keywords}

Food Systems Planning, Planning for Public Health, Public Health D epartment, Formal Plans, Food Policy, G overnment

\section{Introduction and Literature Review}

Food- and $\mathrm{N}$ utrition-related $\mathrm{H}$ ealth

D isparities in the U.S.

Barriers to healthy food consumption underlie many conditions that contribute to suboptimal public health in communities across the U.S. In 2010, four of the top five leading risks factors associated with disease burden in the U.S. were food- and nutrition-related, including dietary risks (i.e., diets low in fruit and vegetables and high in trans fats and processed meats); high body mass index; high blood pressure, and high fasting bloodsugar level (U.S. Burden of Disease Collaborators, 2013). As a consequence, chronic conditions such as heart disease, diabetes, cancer, and arthritis-all of which are influenced by food and nutrition behavior - affect an estimated 50\% of U.S. adults who present at least one chronic condition and $25 \%$ who present multiple chronic conditions (Ward, Schiller, \& Goodman, 2014). Children and adolescents are not immune to these public health concerns. One in three suffers from overweight or obesity (O gden, Carroll, Kit, \& Flegal, 2014), predisposing them to even greater risk of chronic diseases not just later in life but also in childhood and adolescence. What was once referred to as "adult-onset diabetes," or Type 2 diabetes, affects a growing number of young people today, and it has been found to be more difficult to treat among young patients than adults, which bodes very poorly for the future health of Americans (Rosenbloom, Joe, Y oung, \& Winter, 1999). Furthermore, compared to White and wealthier populations, minority and low-income groups must overcome more obstacles to healthy eating and experience a disproportionate burden in chronic diseases (Kirkpatrick, D odd, Reedy, \& K rebs-Smith, 2012; Sijtsma et al., 2012). Taken together, these factors underscore the importance of food not only from a health perspective but also from the perspective of equity and community development.

The Built E nvironment as a U nifying Issue for Public $\mathrm{H}$ ealth and Planning In the face of the growing obesity epidemic, concem about the built environment and its impact on population health has emerged as a unifying issue for the public health and planning fields (Jackson, D annenberg, \& Frumkin, 2013). Collaboration between public health and planning professionals, however, is anything but new (Peterson, 1979). With shared challenges since the late $19^{\text {th }}$ century, this cross-disciplinary partnership has demonstrated some of its greatest strengths by uniting efforts to eliminate public health hazards during the sanitary movement (Sloane, 2006), exchanging knowledge to inform urban renewal demolition and housing policy (Lopez, 2009), and, more recently, harnessing greater attention toward issues related to disparities in food access and health (Caspi, Sorensen, Subramanian, \& Kawachi, 2012). This reunion was in part inspired by a paradigm shift in public health practice in the early 2000s, drawing from the social ecological model and social determinants of health, which considered the multifaceted exchanges between the individual and different levels of the surrounding environment, including the interpersonal, organizational, community, and policy levels (Stokols, 1996; 
Whitehead \& Dahlgren, 1991). As a result, researchers and practitioners across both disciplines banded together to focus on the ways through which the built environment can facilitate or hinder physical activity. Referring to all humanmade structures and surroundings that influence residents' daily behaviors (Botchwey, Falkenstein, Levin, Fisher, \& Trowbridge, 2015), the built environment has been shown to affect physical activity through features such as the mixed use of land, connectivity of street networks, presence of sidewalks and bike lanes, and availability of desirable destinations (Epstein, Raja, G old, Paluch, Pak, \& Roemmich, 2006; Frank, Andresen, \& Schmid, 2004; Frank, Sallis, Conway, Chapman, Saelens, \& Bachman, 2006; Koohsari, Sugiyama, Lamb, Villanueva, \& O wen, 2014; O wen, Humpel, Leslie, Bauman, \& Sallis, 2004; Roemmich, Epstein, Raja, \& Y in, 2007; Roemmich, Epstein, Raja, Y in, Robinson, \& Winiewicz, 2006). Given that these mechanisms between the built environment and physical activity operate within more traditional realms of urban planning (e.g., zoning and transportation), strategies and policies related to modifying the built environment and physical activity have received considerable attention from scholars (Giles-Corti et al., 2016). However, as the obesity epidemic persisted in conjunction with growing critiques that focusing on energy expenditure was insufficient to address diet-related diseases (Luke \& Cooper, 2013), researchers and practitioners in the public health field began to move toward gaining a more holistic understanding of the systemic factors influencing food-related outcomes. On a parallel path, planning scholars were arguing that planning plays a role in food-related outcomes through interventions in the food system. In particular, a now-classic article by Pothukuchi and Kaufman (2000) drew planners' attention to the food system.

Public health and planning interests converged as scholars began investigating the relationships between obesity, diet, and characteristics of the food environment, including the geographic location, spread, and density of food stores selling healthy and unhealthy foods in different neighborhoods, and physical and economic access to those stores (Bridle-Fitzpatrick, 2015; D ubowitz et al.,
2015; E pstein et al., 2012; Jennings et al., 2011; Pothukuchi, 2009; Raja et al., 2010; Rummo et al., 2015; Sloane, 2006). This body of work has motivated a range of programs and policies to improve the availability and accessibility of healthy food. At the national level, revisions to the Special Supplemental Nutrition Program for Women, Infants, and Children (WIC) in 2009 mandated WICauthorized stores to stock a larger variety of healthy items, including low-fat milk, whole-wheat cereals, whole grains, and fruit (Cobb et al., 2015). 0 ther strategies have aimed to modify dietary behaviors by generating greater awareness of the need for a well-balanced diet through nutrition education in schools and after-school programs; food-labeling strategies; anti-obesity and antisugar-sweetened beverages campaigns; and the U.S. D epartment of Agriculture's MyPlate initiative (Sacks, Veerman, Moodie, \& Swinburn, 2011; Story, Kaphingst, Robinson-O 'Brien, \& G lanz, 2008; Tabrizi, Segovia-Siapco, Burkholder, \& Sabate, 2014; Thorndike, Riis, Sonnenberg, \& Levy, 2014). Still, these efforts have been met with limited success in supporting a lasting healthy diet and successful curbing of diet-related chronic diseases (O gden et al., 2016). Poor food environments and the obesity epidemic continue to affect a significant portion of the U.S. population, pointing out the need to better understand the underlying problems in the food system that make it extremely challenging to create and sustain healthy food environments in communities.

F rom the Individual to a Systems A pproach to $\mathrm{N}$ utrition, $\mathrm{F}$ ood, and Public $\mathrm{H}$ ealth

The joint focus on food access and health has progressed and unfolded differently within the fields of public health and planning. Public health scholars have been challenged for their focus on individual-level health determinants and the outcomes of some components of a failed food system, such as the lack of access to nutritious and affordable food (Hodgson, 2012). For planners, however, the issues surrounding food access have been far broader in scope, intersecting with other functional systems of communities, including land use, transportation, open space, and community and economic development (Raja, Born, \& 
Kozlowski Russell, 2008). To address the shortcomings of food systems, pioneers of food systems planning emerging from both the public health and planning disciplines increasingly have called for a more systematic approach (Pothukuchi \& Kaufman, 2000). In 2010, leaders from nursing, nutrition, planning, and public health joined forces to create a shared statement focused on "systemwide food policy change" (Hodgson, 2012). This shared statement includes a set of values, visions, and principles that has guided the respective disciplines in their efforts to encourage a healthy, sustainable food system. ${ }^{1}$ While this early document was more focused on defining visionary goals, the continued collaboration between the American Planning Association (APA) and American Public Health Association (APHA) has produced more detailed guidelines and actionable plans to implement and plan for healthy communities. Of recent efforts is a joint call for action, culminating in the Plan4Health project that aims to bring together APA and APHA members, use their complementary expertise, build capacity, and provide guidelines and tools to create a healthier and more equitable community. ${ }^{2}$

Public $\mathrm{H}$ ealth D epartments in Planning for $\mathrm{H}$ ealthy and Sustainable F ood Systems LRM governments use a wide range of policy tools to evaluate current conditions, set goals, and implement strategies and actions to guide communities toward an envisioned future (Hodgson, 2012). Key tools used by planning departments include a variety of formal plans to assess and address challenges in areas ranging from housing and economic development to land use and transportation. These plans vary based on their scope, scale, urgency, and legal authority. For example, comprehensive plans, sometimes called general plans, which are characterized by their holistic and integrated approach covering entire communities, are the most prevalent type that sometimes bear legal authority to fulfill a long-term vision by state-enabling legislation. Particular problems or subjects are addressed through functional plans, including open space plans, community health plans, housing plans, and more recently food systems plans (Raja \& Whittaker, 2018). Subarea plans focus on a particular subarea within a local jurisdiction, such as a corridor or neighborhood. Last but not least, planners can adopt strategic plans to address urgent or highpriority problems such as those focusing on sustainability and climate change issues (Hodgson, 2012).

The aforementioned plans can have a direct or indirect and lasting influence on the health and well-being of communities. They can inform local government budgetary decisions, regulations, and ordinances. Nevertheless, until recently issues of food and public health have been largely absent from these official plans. In the past decades, planners have argued that issues related to food production, preparation, processing, distribution, consumption, and waste management intersect in a wide range of ways with other major, if not conventional, planning realms, such as land use planning (e.g., urban food production, farm preservation) (Connell et al., 2013), environmental planning (e.g., climate change and food production) (Rosenzweig, Iglesias, Yang, Epstein, \& Chivian, 2001), transportation (e.g., access to food outlets) (Clifton, 2004), and community and economic development (e.g., job and income generation) (Vitiello \& Wolf-Powers, 2014). As such, this "puzzling omission" (American Planning Association, 2007) of food from the formal planning education and practice (Morgan, 2009; Pothukuchi \& Kaufman, 2000) has diminished in recent years, with a modest growth of municipalities' involvement in addressing food-related issues. For example, a 2008 survey of APA members $(n=192)$ demonstrated that a significant percentage of respondents were involved in land-use planning (20\%), comprehensive planning (14\%), and community development (14\%). However, only $2.5 \%$ of planners worked primarily in the area of community and regional food planning (Raja et al., 2008). A subsequent survey of APA members $(\mathrm{n}=888)$ focused on comprehensive or sustainability plans revealed that just over $10 \%$ of local

\footnotetext{
${ }^{1}$ See http:/ / planning.org/ nationalcenters/ health/ foodprinciples.htm

2 See https:/ / www.planning.org/ nationalcenters/ health/ calltoaction/
} 
governments in the U.S. $(\mathrm{n}=80)$ had a comprehensive plan or sustainability plan $(n=20)$ that explicitly addressed one of the food system components (Hodgson, 2012).

While these recent findings shed light on the gradual growth of food-related plans and policies, there remains a great need to further understand how the field can fully integrate planning for food and health. In particular, the way food systems is treated across the spectrum of formal plans-in addition to comprehensive and sustainability plans - is not yet known. Furthermore, given the close ties between food and health, scholars and practitioners from both fields of planning and public health have been revisiting the roles that both professions can play in promoting healthy communities. Specifically, public health departments are given responsibility for creating and maintaining conditions to support healthy communities, yet the ways in which they engage in food systems planning is understudied. To fill these gaps in knowledge, this study aims to (1) examine the extent to which food systems is addressed in a range of formal plans adopted by LRM governments; (2) assess how formal plans address food systems (i.e., do plans undermine or strengthen food systems); and (3) investigate how public health agencies engage in food systems planning.

\section{Research Design and Methods}

The paper draws on the data from the Growing Food Connections (GFC) project, a federally funded, national initiative focused on local government capacity in food systems planning (https:/ / growingfoodconnections.org). From 2012 to 2017, the GFC team - composed of the core research team, a national advisory committee with representation from diverse disciplines and regions, and the American Planning Association - engaged in a policy action research initiative to enhance food security among consumers while ensuring sustainable and economically competitive agriculture among struggling farmers in vulnerable communities across the U.S. (Raja, Whittaker, Hall, Hodgson, \& Leccese, 2018).

The team employed a sequential research design. First, the team conducted a national survey of planning practitioners in 2014. This was followed by in-depth interviews in two types of selected communities: places where local governments had adopted plans and policies to strengthen the food system, or what we termed communities of innovation (CO Is), and places that showed an opportunity for policy change, or what we termed communities of opportunity (CO Os). Finally, we conducted capacity-building work in CO 0 s and, subsequently, additional interviews (Raja et al., 2018).

This paper relies on a subset of data from the GFC project, specifically the 2014 national survey data and the qualitative interviews from CO Is. Contender CO Is were identified following a national scan that included a review of grey literature, review of prior survey data, and referrals from national experts, as well as the GFC national advisory committee. Through the national scan, the team identified 299 local governments across the U.S. that were developing and implementing a range of innovative plans, public programs, regulations, laws, financial investments, and other policies to alleviate food insecurity and bolster agricultural viability among small and medium-sized farmers. The GFC team narrowed down these 299 communities to $22 \mathrm{CO}$ Is where LRM governments played a significant role in implementing innovative policies that strengthen the food system. Finally, the team conducted exploratory telephone interviews that resulted in 2 candidate $\mathrm{CO}$ Is being dropped and thus ended up with a final sample of 20 CO Is. A more detailed description of the GFC project may be found in previously published work (Clark, Freedgood, Irish, Hodgson, \& Raja, 2017; Raja et al., 2018).

This paper provides (1) a descriptive analysis of formal plans adopted by LRM governments to provide an expansive national perspective of food systems planning by drawing on survey results, followed by (2) a qualitative cross-case analysis based on semistructured interviews with LRM governments in CO Is to provide a deeper understanding into the ways that food systems planning operates in different settings (urban versus rural). Detailed methods of data collection for the survey and qualitative research in $\mathrm{CO}$ Is are described below. 
Cross-sectional Survey of $\mathrm{L}$ ocal $\mathrm{G}$ overnment Planning The first phase of the study relied on data collected from a national survey administered online and directed to all members of the American Planning Association (APA) in 2014. The survey inquired about the ways in which practitioners used policy tools to strengthen community-based food systems. A community's food system was defined by the interdependent activities, resources, stakeholders, and regulations that enable food to be grown, processed, distributed, and acquired by consumers, and food waste to be disposed of in a sustainable way within a community. The survey instrument was piloted with individuals practicing in the core areas of inquiry, including local government planning, agriculture, food access, and food systems planning. Pilot respondents reviewed the instrument, and feedback on questions that were unclear, redundant, or missing was incorporated into the final survey before the deployment to APA membership. Pilot respondents were ineligible to complete the final survey. The survey was approved by the Institutional Review Board at the State University of New York at Buffalo.

Study Participants

The APA membership includes approximately 30,000 people. Of these, 3,103 members (10\%) responded to the survey, a response rate that is statistically representative of the full APA membership. ${ }^{3}$ More than one-third of respondents reported working for or on behalf of LRM governments. This analysis is based on the data extracted for these 1,169 respondents who reported working for or on behalf of LRM governments in the U.S. The survey was distributed to all APA members via an e-mail message from the leadership of the APA. E-mail reminders were sent to nonrespondents within two weeks of the original invitation to participate in the survey. Respondents received no monetary compensation for their participation.

Survey M easures Seventeen questions, and additional subcategory questions, in the survey queried about respondents' characteristics (e.g., familiarity with food systems planning or professional involvement with food systems planning) and the use of plans (e.g., longrange plans supporting food production, aggregation, processing, distribution, and sale) and implementation tools (e.g., regulations, budgetary decisions, and development incentives supporting the food system) by respondents' LRM governments. This paper focuses on a subset of questions from the larger survey, specifically those evaluating the use of formal plans in strengthening food systems (Raja, Raj, \& Roberts, 2017; Raja et al., 2018). Respondents were asked to evaluate the ways in which plans adopted by their LRM governments affect the food system in communities. Respondents chose from a set of 13 formal plans that included agriculture and/ or farmland protection plan; comprehensive plan; climate change plan; community health plan; economic development plan; environmental plan; food system plan; housing plan; land use plan; open space plan; recreational plan; sustainability plan; and transportation plan. Selection of formal plans to include in the survey followed several procedures, beginning with an assessment of peer-reviewed and grey literature as well as consultation with food systems planning practitioners. Respondents also had the option of specifying and evaluating other formal plans not included in the survey, by answering in an open text box.

Respondents evaluated the ways in which formal plans affect the food system, by indicating whether a plan "does not exist," "exists but undermines the food system," "exists but does not make any explicit reference to food systems," "exists and strengthens the food system," "strengthening the food system is a key priority," or "I do not know." Respondents working for LRM governments that adopted a food system plan and explicitly made the food system a key priority were directed to select "strengthening the food system is a key priority," while respondents working for LRM governments that were not explicit in making the food system a priority, but made efforts to address some issues in the food system, were directed to select "exists and strengthens the food system."

\footnotetext{
${ }^{3}$ A sample size from a population of 30,000 with a 95\% confidence interval and a 5\% margin of error requires 385 respondents.
} 
Survey data were analyzed to gauge broad national trends in how LRM governments are engaging in food systems planning. We performed descriptive data analyses using Microsoft Excel.

Stakeholder Interviews with Public $\mathrm{H}$ ealth and Planning E ntities in an U rban V ersus Rural Setting We supplemented the analysis of broad national trends from survey data with in-depth exploration of the ways in which food systems planners engage with other LRM government entities, particularly focusing on public health agencies. We conducted a qualitative analysis, drawing from stakeholder interviews from selected CO Is in the GFC project.

In-depth interviews

To gain a deeper understanding of the novel strategies employed and reasons for success in CO Is, the research team conducted semistructured interviews with stakeholders in each COI. The list of interviewees in each COI was compiled using web searches focused on identifying local government entities that engage in food systems planning, and was later expanded based on interviewees' referral. Interview questions queried about public policy responses in community food production and food security (i.e., challenges, opportunities, and notable stakeholders involved in the adoption and implementation of food system policies).

\section{Cross-case analysis}

All interviews were audio-recorded and transcribed by a professional transcription service. Transcriptions were coded manually and analyzed separately by two research team members. Codes were compared to identify key themes, consistencies, and differences in the two selected communities. Additionally, policies mentioned in interviews were cross-referenced to further examine how those policies strengthened food systems. A preliminary report was prepared for each CO I. Using analyst triangulation, findings in the preliminary report were assessed by a third party that included lead stakeholders in each community, to further corroborate our findings.

To illuminate how planning and public health agencies intersect and collaborate in an urban versus rural jurisdiction, we report on interview findings from two $\mathrm{CO}$ Is, one urban and one rural: Philadelphia, Pennsylvania (PA; $n=3$ ) and Region 5, Minnesota (MN; $n=7)$. In particular, we examine the public health-planning relationship by focusing on the process of plan and policy-making, the role of local engagement, and the strengths and challenges in developing food-related plans and policies.

C ase study settings: Philadelphia, PA , and Region 5, M N Philadelphia represents an urban community with a long-standing history of a local health department's focus on urban food access issues. Philadelphia is home to over 1.5 million people in the heart of the D elaware Valley, where fresh fruits and vegetables, meat, poultry, dairy, and eggs are the main agricultural products. In this region, growers on small to medium-sized farms experience major difficulties related to a lack of local processing capacity, soil contamination, and limited access to water. Urban growers also experience challenges with profiting in the city, resulting in produce sales made to restaurants rather than to local residents. This disconnect between local food production and food access is troubling because for residents, many of whom suffer from extraordinarily high poverty rates and little to no walkable access to healthy food retailers, food insecurity is also a grave issue. Further, the latest community health assessment reported that the prevalence of adult obesity has increased 5\% since 2002, with black Philadelphians experiencing greater adult obesity, hypertension, diabetes, and less healthy food access (Philadelphia D epartment of Public Health, 2015).

Region 5 is an example of a rural jurisdiction where the local health department is part of an interagency collaborative effort to strengthen the food system. Region 5 is located in central Minnesota and consists of five counties (Cass, Crow Wing, Morrison, Todd, and Wadena), all of which are the most economically distressed in the state. Approximately 163,000 people live in this rural area, which is known for its poultry and eggs, cow milk, cattle, turkeys, grains, dry beans and peas, and over 70 varieties of vegetables. In spite of the agricultural wealth and diversity, Region 5 growers and residents face significant challenges in their food system. D ue to its location in the northern 
U.S., the growing season in Region 5 is severely limited, and food is generally inaccessible and unaffordable for many residents, particularly during winter months. According to Cheryal Hills, executive director of the Region 5 D evelopment Commission, approximately $10 \%$ of the population in all five counties is food insecure, with the greatest prevalence of food insecurity occurring in Wadena County at $13 \%$. The proportion of children eligible for free lunch is well above the state average (30\%) in Cass County (52\%) and Todd County (42\%).

\section{Strengths and L imitations}

The strengths and limitations of this study are worth considering. This work builds on prior research by assessing where the food system is addressed across the wide range of official plans that LRM governments adopt and implement, with a particular focus on the ways in which public health departments support healthy and equitable food systems planning. Additionally, the analysis includes a sizable and statistically representative sample of planning practitioners from LRM governments across the U.S. However, the completion rate of questions related to food systems plans adopted by LMR governments was relatively low at approximately $50 \%$ (of practitioners who work for or on behalf of LRM governments). We believe this low completion rate is telling in itself, in that the other half of respondents may not have any official plans in place or may have limited capacity - that is, minimal familiarity or involvementwithin their LRM governments to implement food systems planning, thus making it less likely for nonrespondents to answer questions related to food system plans. Qualitative findings from this study offer insight into how public health departments, in particular, can join with the planning field to facilitate the development and implementation of food systems policies. Future research could benefit from further exploring the barriers and challenges nonrespondents may be facing in relation to adopting plans that support and strengthen the food system.

\section{Results}

Cross-sectional Survey of L ocal G overnment Planning: Sample C haracteristics O ur study sample $(n=1,169)$ included practitioners who worked for or on behalf of LRM governments mostly serving suburban or urban districts, followed by rural, exurban, and other areas; other areas included small towns, mountainous regions, or a mix of both urban and rural jurisdictions (Figure 1). Respondents had the option to report working for more than one area. The top organization through which respondents were involved in planning was local government (Figure 2). Nearly half of all respondents (49.4\%) reported

Figure 1. Number of Respondents Working for or on Behalf of Local, Regional, and M etropolitan (LRM) Governments Serving Urban, Suburban, Exurban, Rural, and Other Areas

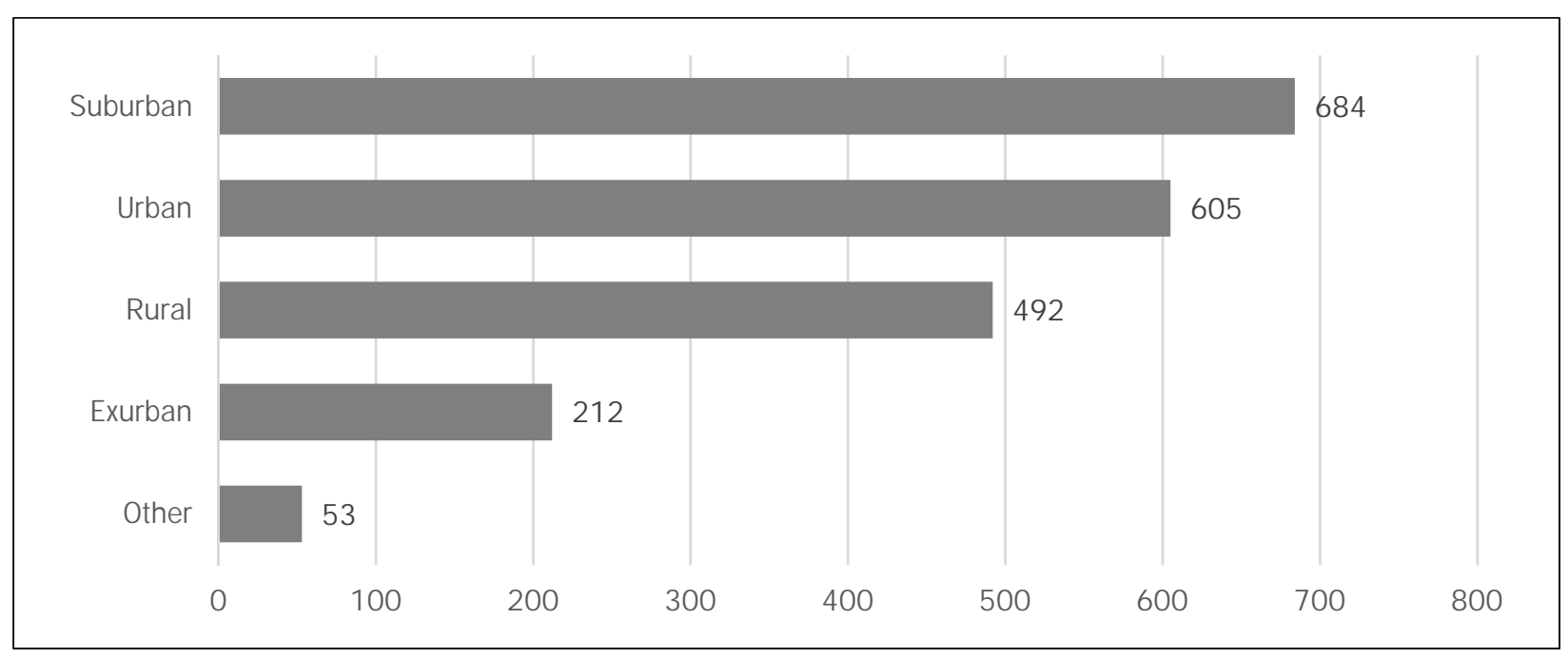


having earned a graduate degree. In regard to field of training, 489 respondents completed degrees in planning, 12 in public health, and 1 in both planning and public health. Women and men composed $34 \%$ and $32 \%$ of respondents, respectively, and the remainder chose not to report their gender. Seventy percent of respondents had more than 5 years of experience in the planning profession (not shown).

Cross-sectional F ood Systems Survey: F ood Systems in A dopted F ormal Plans

This subanalysis was based on completed results from 584 to 590 respondents (the number varied depending on the plan in question) who reported on formal plans adopted by their LRM governments and evaluated the ways in which those plans affect food systems.

Taking into consideration plans that have a particular focus on food systems, our findings show that all had adopted formal plans prioritize and strengthen the food system, but to varying degrees (Figure 3). Comprehensive plans were most likely to treat the food system as a key priority and to strengthen the food system, as reported by $5 \%(n=30)$ and $25 \%(n=147)$ of respondents, respectively. In particular, California and Washington ranked the highest for the

Figure 2. Proportion of APA Member Respondents Employed by Local, Regional, and Metropolitan (LRM) Governments $(n=1,169)$, by Type of Organization

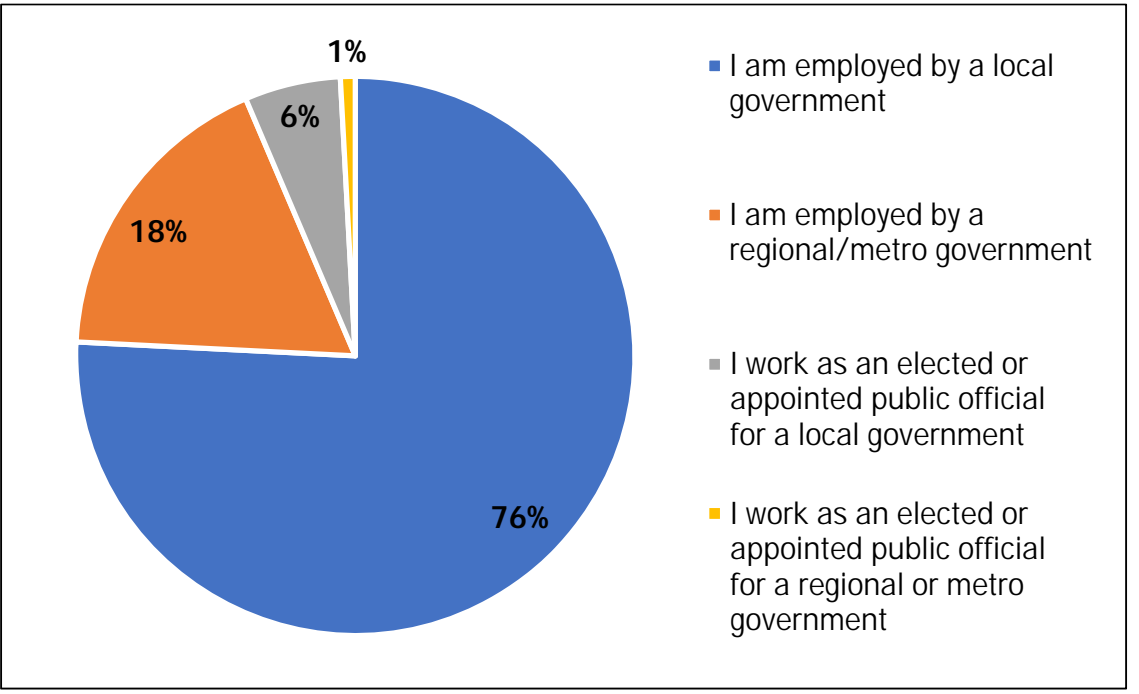

adoption of comprehensive plans that strengthen the food system, whereas Hawaii and Arizona ranked the highest for prioritizing the food system in their comprehensive plans (not shown). Community health plans, which could be an area where planners and public health practitioners collaborate, also appear to view food systems as a priority among $3 \%$ of respondents $(n=18)$ and to strengthen the food system among $13 \%$ of respondents $(\mathrm{n}=77)$. Additionally, agriculture and/ or farmland protection plans, sustainability plans, economic development plans, and open space plans were comparable to community health plans in terms of prioritizing and strengthening the food system. Interestingly, even though very few LRM governments adopt transportation or housing plans that make the food system a key priority, respondents suggest that such plans can still strengthen the food system.

In terms of plans that threaten the food system, transportation and economic development plans were most commonly described as undermining the food system, as opposed to agriculture and/ or farmland protection, food system, and climate change plan, which were least commonly described as undermining the food system (Figure 4). All formal plans reportedly strengthen food systems to a greater extent, as opposed to undermine the food system, with the exception of transportation plans. For example, while $14 \%$ of respondents shared that economic development plans strengthened food systems, compared to the $4 \%$ who shared that economic development plans undermine the food system, transportation plans were almost equally likely to be reported as both undermining $(5 \%)$ and strengthening $(6 \%)$ the food system.

Lastly, there is considerable variability in the formal plans adopted by LRM governments overall. Comprehensive, land use, and 
transportations plans were the most prevalent among respondents' LRM governments, while plans ex clusively related to the food system were largely nonexistent. Specifically, stand-alone food systems plans did not exist for $69 \%$ of respondents, and this was followed by climate change plans (60\%), farmland protection plans (47\%), community health plans ( $44 \%)$, and sustainability plans (44\%). Findings also reveal sizable variability in the explicit reference to food systems among adopted plans. More than half of respondents reported that there was no explicit reference to food systems among existing transportation plans (63\%), recreational plans (55\%), land use plans (53\%), and comprehensive plans (51\%), separately. Community health plans and climate change plans had the smallest gap to close, with $13 \%$ and $16 \%$, respectively, of adopted formal plans that did not explicitly reference the food system. Surprisingly, $4 \%$ of respondents reported that although their LRM governments adopted a food systems plan, there was no explicit reference to food systems. One plausible explanation is that the adopted food systems plan did not actually carry a systemic perspective.

Cross-case F indings on the R ole of $\mathrm{Public} \mathrm{H}$ ealth in U rban versus Rural F ood Systems Planning

Comprehensive food systems planning and policy in Philadelphia

The Philadelphia local government has demonstrated a uniquely strong commitment to food systems planning and policy over the last decade. D riven by the collaborative leadership of the Mayor's O ffice of Sustainability and the D epartment of Public Health, activities in this urban jurisdiction shed light on the strengths of planning under the public health umbrella of antihunger and preventing chronic disease. O ur findings reveal that the comprehensive sustainability plan was an anchor in bringing diverse stakeholders together to facilitate a suite of policies to promote equitable access to healthy food. Furthermore, the success of the sustainability plan that incorporated public health goals was made possible due to a

Figure 3. Comparison of Formal Plans Adopted by Local, Regional, and Metropolitan (LRM) Governments that Include the Food System as a Key Priority and to Strengthen the Food System

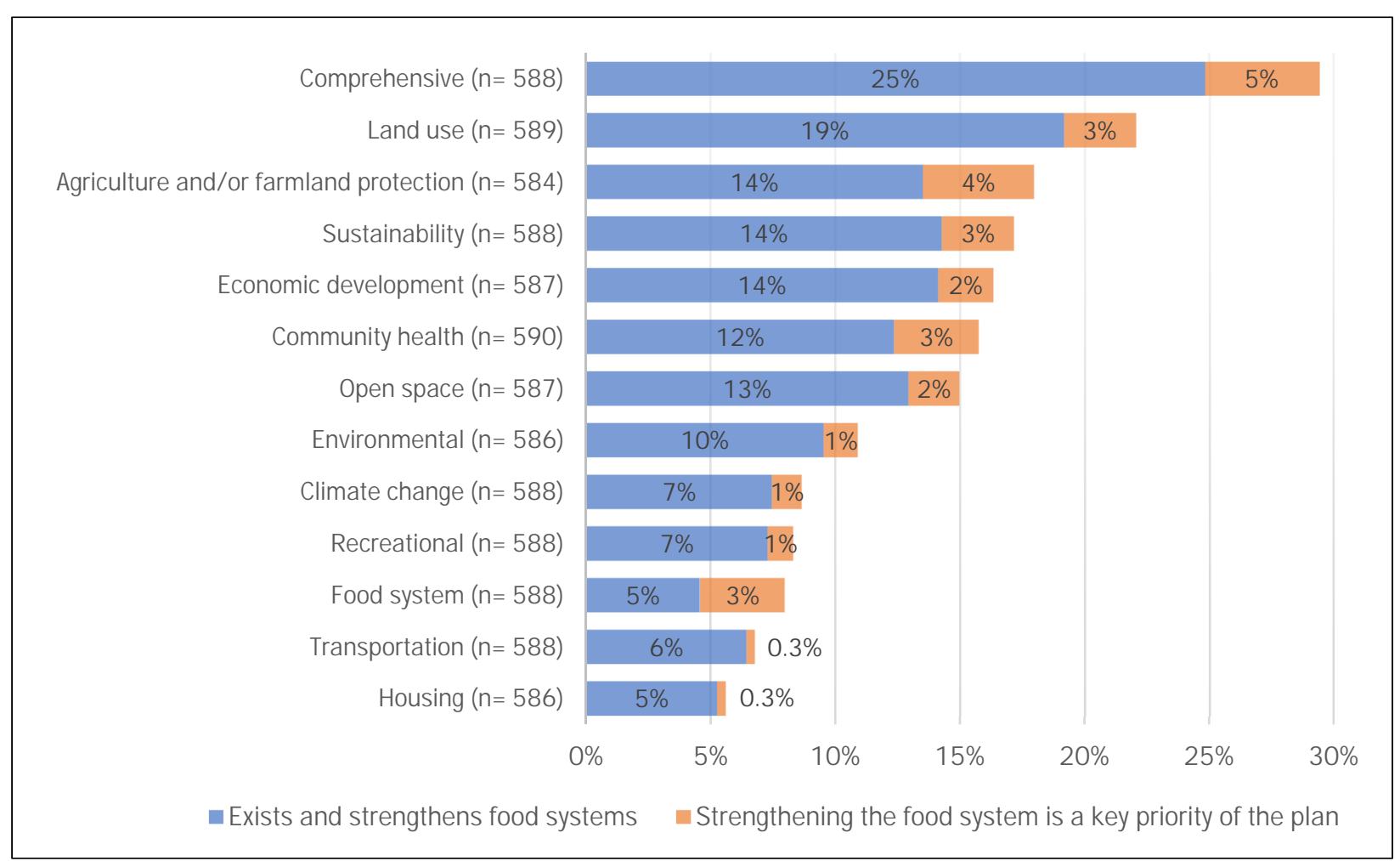


Figure 4. Formal Plans Adopted by Local, Regional, and Metropolitan (LRM) Governments that Address Food Systems

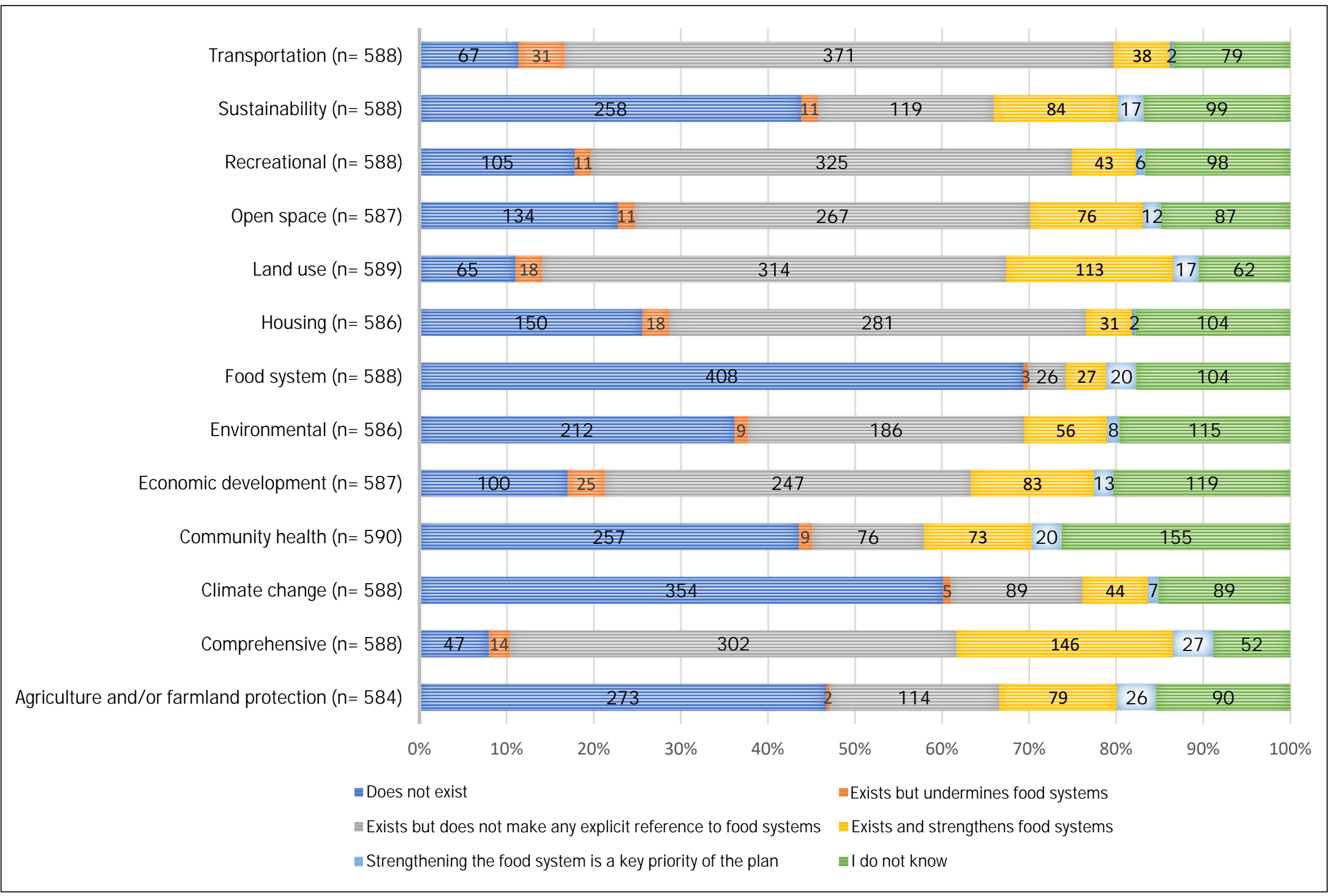


history of grassroots efforts, civic engagement, and food-related advocacy in Philadelphia:

We have a rich history of gardening in Philadelphia [since the] mid 70s and 80s when there was lots of disinvestment in the city. (August 23, 2013)

D espite the long history of urban food production in Philadelphia, it was not until 2008 that the local government took a proactive approach toward food and urban food production in the city. In 2008, then Mayor Michael Nutter established the Philadelphia Food Charter, pledging to support a food system that benefits the community, economy, and environment of Philadelphia. Soon after, Mayor Nutter's commitment to make Philadelphia the greenest city in America resulted in establishing the Mayor's O ffice of Sustainability, which served as the champion of the $\mathrm{G}$ reenworks Philadelphia Sustainability Plan in 2009. This is Philadelphia's comprehensive sustainability plan, which includes eight visions, one of which focuses on access to healthy, affordable, and sustainable food and drinking water. O ne LRM government representative emphasized the advantages of utilizing a comprehensive plan that focused on food and health, under the leadership of the administration and public health department:

The biggest opportunity right now is that there is an administration that is involved in green work. O ur comprehensive plan has a food access goal. There is the health department that is strongly working on the food access. (August 23, 2013).

Critical to note is the historical and ongoing advocacy work in Philadelphia that reinforced governmental food-related policies and programs. In particular were the efforts of the Next Great City Coalition, which put forth an urban environmental agenda that motivated and informed the G reenworks Philadelphia Sustainability Plan:

\footnotetext{
${ }^{4}$ See http:// www.phillyfpac.org
}

Greenworks was a reaction to a community organization movement called the Next G reat City in Philly- a coalition of external groups that got together and facilitated community meetings where people listed their priorities... The N ext Great City asked each mayoral candidate [about] a topic that the people cared so much about. This was one way the city realized that food was such a big issue with people. (August 23, 2013)

Last but not least, then Mayor Nutter's Food Charter established the Philadelphia Food Policy Advocacy Council (FPAC) 4 in 2011. FPAC members and supporters collaborate to advocate and develop policy recommendations for the city, through regular general meetings and executive sessions. Particularly critical to FPAC was the council's intentional recognition of the value of inclusion, defined by age, socioeconomic status, gender, race/ ethnicity, education, and more, in its membership and the food systems planning process for the city. This was operationalized through shared leadership and accountability and trust-building, as well as flexible and adaptive practices. As noted during an interview:

[The FPAC] is doing a great job of getting a representative voice of Philly to the council. (August 23, 2013)

The aforementioned findings from Philadelphia point to how the partnership between public health and inclusive planning was a reinforcing process that strengthened the urban food system by providing financial and human resources, advancing a regional food system planning agenda, and instigating the development of other foodrelated polices and programs. We found that both planning and public health departments dedicated financial and human resources to working across departments and throughout the administration, connecting both food production and food security efforts. The joint resources helped to fund some of the most innovative food system plans and programs in Philadelphia, including the G reenworks 
Philadelphia Sustainability Plan, Philadelphia 2035, the Food Charter, Philadelphia FPAC, and Get Healthy Philly. With Philadelphia's local health department as a major partner in the planning process, the scope of planning shifted to include the regional context in addition to the local. For example, dedicated to creating a food systems that is healthy and sustainable, the FPAC brought together perspectives from key city and regional stakeholders around the importance of connecting local and regional food to public health. One LRM government representative shared:

With the food policy advisory council, we have a new subcommittee looking at food procurement in the city... We are examining which agencies in the city buy food and what they buy, and if the regional food production would meet the health and nutrition requirements that the health department needs to fulfill with food producers. We are not thinking about just Philly produced food, but regionally produced food as a whole. (August $23,2013)$

Additionally, the public health and planning departments, along with other stakeholders, successfully deployed a line of food systems strategies under the G et Healthy Philly (G HP) initiative. Because public health departments interface with all levels of government, from local to state and federal, our findings also suggest that public health agencies offer an ability to secure funding from a wider range of resources to support food systems planning and implementation. For example, spearheaded by the Philadelphia D epartment of Public Health, funding for GHP was awanded through the Communities Putting Prevention to Work initiative of the U.S. Centers for D isease Control and Prevention (CD C). Under the goal of chronic disease prevention, GHP was established in 2010 as a groundbreaking collaborative initiative, including individuals from academia, local government, the private sector, and community organizations, to address physical activity, smoking, and nutrition in Philadelphia. Citywide efforts spearheaded by GHP include the Healthy Corner Store Program, Healthy Carts Program,
Philly Food Bucks, as well as funding for establishing nine new farmers markets in lowincome communities. Philly Food Bucks was particularly innovative by increasing the purchasing power of lower-income farmers market shoppers by $40 \%$. Lastly, G HP funded a food policy coordinator for the city. Initially supported by the $\mathrm{CDC}$ grant, this position was later formally established as a salaried position with the Philadelphia D epartment of Public Health.

Findings also suggested that the inclusion of food in the comprehensive sustainability plan initiated a ripple effect, influencing other planning processes to incorporate food system policies and strategies in the zoning code rewrite, 18 district plans, the regional transportation sustainability plan, and the parks and recreation department's work, to name a few examples (Hodgson, 2012). One interviewee pointed to the ways that the Southeast Pennsylvania Transportation Authority (SEPTA) supported increased access to healthy food by developing plans for a new supermarket next to one of its bus stations, as well as leasing land next to one of its stations to community members for growing food.

Ultimately, Philadelphia's leadership, bolstered by the local public health department and other key partners, led to a stream of successful inclusive planning for an equitable food system and public health. Even more, these achievements have influenced the focus on health in the city's 2011 comprehensive plan, Philadelphia 2035.

F ood Systems Planning for E conomic D evelopment in Region 5, Minnesota Motivated to improve food insecurity and economic distress, Region 5 Development Commission (R5D C), Todd County Health D epartment, several healthcare entities, and local governments have worked together to transform food systems planning and policy in this rural jurisdiction. Similar to the case in Philadelphia, the involvement of the public health department, development of a comprehensive sustainability plan, and geographical context were important in supporting food systems change. However, findings from our interviews reveal differences in how the health 
department interacted with planning to strengthen the regional food system.

In 1969, Region 5 D evelopment Commission (R5D C) was established and charged with coordinating comprehensive planning and program development at the state, federal, and local levels to address economic, social, and physical issues in the region. Like Philadelphia, the joint effort for building a stronger food system was initiated with a statewide food charter to "set forth policy objectives for [Minnesota] to run local foods" (Interviewee, August 6, 2015). The food charter focused on issues around accessibility and affordability of food. In this context, however, rather than planning under the umbrella of chronic disease prevention, Region 5 focused on identifying opportunities for economic development to lift all counties out of economic distress. Additionally, because agriculture is recognized as a particular strength in this region, results from our interviews shed light on how this signaled an opportunity for planning, public health, and other local government to leverage the community food system to build a stronger local economy:

O ur connection to local food is economic development, because this is an industry... Those farmers are businesses, they are running a business. So that was a natural connection to job creation and retention. (August 6, 3015)

Such a cross-sectoral collaboration was promoted by the ways that the food charter, as a state policy, directed money from the departments of agriculture, health, and economic development to set the course on how local foods could be supported. As such, R5DC has served as the key coordinator for the region's food system planning. Insights from our interviews further illustrate how the planning process motivated cross-sector relationships among food system stakeholders and served as a major driver in food system change in Region 5, culminating in 2012's Central Minnesota Sustainable D evelopment Plan. Unique to this planning process, also known as the Resilient Region Project, was the use of an inclusive civic engagement model, in which R5DC actively sought out input from over 600 residents across the region over two years (Region Five D evelopment Commission, 2012). Furthermore, less common partners were brought together to focus on food, such as transportation and community and economic development agencies. This is partly explained by the ways that the LRM governments define and interpret a sustainable and a resilient region. O ne of the interviewees noted that:

Through the recession, [the food charter] focused on retention not so much creation. So, it seemed to be an immediate critical issue to make sure that we could sustain and to be resilient means to somewhat be able to sustain yourself and that includes a good water and food supply. For me, that connection to economic development clearly was the jobs, the retention, the essential needs. (August 6, 3015)

Adopting an economic development framework for a stronger food system and implementation of community engagement practices has led Region 5 not only to focus on food access and health dimensions of food systems planning, but also to center on creating a regional food system that generates local wealth for small to mediumsized producers and processors. Strategies include establishing a variety of financial and educational programs for small growers developing a regional farm-to-institution program to support growers, while improving food access for vulnerable populations, and constructing a food infrastructure to assist in the aggregation, processing, and/ or distribution of products for local growers.

Similarly, focus on the two most vulnerable populations within the local and regional food system - those without adequate access to food as well as small to medium-sized growers- was the main objective for one of the region's landmark programs: Choose Health. Choose Health, facilitated by the food charter and established in 2014, is a comprehensive program that relies on a publicprivate partnership among multiple organizations such as Lakewood Health System, a regional food hub (known as Sprout), Todd County Health D epartment, University of Minnesota Extension, 
and Prairie Bay Restaurant. O ne of the interviewees pointed to the strengths of this comprehensive program:

[O ne] food access to population that don't have access. Two is the grower incomes. That we are allowing family farmers to be livable wages [sic]. We have focused on minority growers and those that have not had access to markets like our Amish growers and low- income growers for our markets not large production farms that are already doing pretty well. (August 6, 3015)

Findings from Region 5 highlight how the county public health department was particularly important in providing stable, dedicated funding as well as technical support to move food systems change forward in Region 5. Choose Health is particularly illustrative of the role of the health department in food systems planning in this context. Beginning as a six-month pilot project funded by Hunger-Free Minnesota, the program is currently sustained by additional funding from hospitals and healthcare practitioners in the region. According to interviewees, establishment of such a partnership was challenging at the beginning since the Choose Health program did not focus on hunger relief as much as it did on food security, and they perceived the R5D C merely as an economic development entity. However, all partners in the program eventually moved beyond their more conventional practices in order to make the Choose Health program work. O ne way that the health agencies, especially hospitals, were able to financially support the program was through the federal tax code changes of 2014. The new tax codes allowed nonprofit hospitals to purchase local foods and pay for community supported agriculture (CSA) memberships as a remediation for obesity or mental health. One interviewee mentioned that this mechanism enabled a sustainable funding source for the program and brought support from the health care system:

... That's why the other hospitals started calling... because [this] wasn't an additional expense to them. It was part of their tax write-off and eligible part of their tax dollars that they had to spend in this purpose anyway. That was really important and Choose Health has also been sustainable through the O bama Administration, and whether you like it or not the whole [Affordable] Care Act, you can now purchase a CSA with your HSA dollars, your health saving account. (August 6, 2016)

In addition to the financial support, the Todd County Health D epartment provided ongoing technical support, staffing, and a community referral process. Participants of the Choose Health program go through an extensive pre- and posthealth-care screening, followed by nutrition education and recipes from the University of Minnesota. Families also receive locally grown and raised commodities bi-monthly from Sprout, the five-county regional food hub of more than 70 local lowincome growers. Preliminary evaluation of the Choose Health program indicates greater access to fruits and vegetables and increases in fruit and vegetable consumption by participants, both of which are promising indicators of improved health outcomes. O ne respondent explained how this partnership allows one to assess the current state of community needs as well as measure process and success, such as healthier eating:

In addition to collecting local data through department resources, Todd County Public Health has been working with hospitals to be more involved through accurately collecting data and sharing reports... Community health needs assessment and community health survey [are] done every three years. Todd County's Public Health D epartment [use of] other methods and tools include collects qualitative data through one-on-one interviews and focus groups. (August 6, 2015)

This is especially important given the fact that Minnesota is one of the states that disbanded their state planning organizations, meaning there is no central location and organization that can lead and manage data collection. While many organizations 
stepped up to fill this gap, such as farmer unions and state economic development organizations, public health professionals were the key players in data collection efforts. Ultimately, with this support from Todd County Health D epartment, the implementation of the Central Minnesota Sustainable D evelopment Plan was strengthened with more strategic tracking that ensured needs were being met where it was needed most.

\section{Discussion}

Relative to other formal plans, planning for the food system still largely does not exist as mainstream planning practice. Results from this study indicate that it is more common for formal plans to focus on some components of the food system and less likely for stand-alone plans to exist. This indicates that unlike other infrastructure, such as transportation and housing, the food system still is not viewed as one that LRM governments are obligated to invest in with intention and a long-term vision. With that said, food systems planning has gained slow and steady momentum over the last decade, pointing to opportunities for further strengthening. Our quantitative results show that a greater proportion of comprehensive plans were reported to strengthen the food system and make the food system a key priority in the plan, and our qualitative findings reveal how the process of developing comprehensive sustainability plans was made stronger by investments from both planning and public health in an urban versus rural setting.

Overall, public health departments are well equipped with metrics on people and communities to identify areas of greatest need and to guide the ways in which planning and its tools (e.g., formal plans) can be maximized to support health. O ur findings build on prior literature by offering strategies to leverage the strengths of public health departments in food systems planning. In particular, public health departments can effectively mobilize other public and private entities to influence funding streams, by securing grants and other financial support; food access policies, by providing technical assistance and programmatic support; and structural changes within government agencies, by establishing formalized committees or salaried positions dedicated to food.
Moving forward, more regular interfacing between public health and planning departments is needed to strengthen food systems planning. To build on current efforts, LRM governments are well-positioned for (1) better connecting practitioners in the planning and public health fields; (2) identifying shared goals across departments; and (3) capacity-building to plan, implement, and evaluate food systems. Additionally, the different ways in which engagement between public health and planning can unfold depend on context (historical and geographical) as well as existing community assets.

To leverage the strengths of both disciplines and bolster their reach and impact, LRM governments can institutionalize cross-collaboration by establishing a formal interdepartmental agency or working group. In practice, public health occurs in many domains, from nutrition to disease prevention to occupational safety. Specific strengths of public health departments include the ability to provide evidence of the human health effects of a range of exposures and identify areas of greatest need through strategic data collection as well as the documentation of health outcomes and health disparities. Meanwhile, the plan-making process calls for a range of stakeholder groups to actively participate in the development, adoption, implementation, and evaluation of formal plans that ultimately influence and shape communities. For planning departments that are addressing food systems issues, advantages include a systems perspective by making connections between a variety of interconnected social, economic, and environmental issues, including quality of life, economic opportunity, environmental justice, and food issues. In particular, the Philadelphia Food Policy Advisory Council and Region 5 D evelopment Commission illustrate how cross-disciplinary coalitions can move food systems planning forward in a more systematic and meaningful way. Leadership in Philadelphia from the mayor and health commissioner resulted in the development and implementation of the Greenworks Philadelphia Sustainability Plan, which catalyzed comprehensive planning for sustainable programs and food systems. Similarly, cross-sectoral leadership in Region 5, involving R5DC, the county public health 
department, and local government, culminated in the Central Minnesota Sustainable D evelopment Plan and the deployment of novel approaches that addressed food insecurity and economic distress.

Both cases also exemplify how comprehensive sustainability plans can be leveraged to strengthen food systems and beyond. Because stand-alone food system plans are often strategic plans with a shorter time frame, one approach can be to leverage comprehensive plans- which are also often required by state government statute and shape long-term decision-making for a jurisdiction - to make food systems strategies more conventional among LRM governments moving forward. A qualitative exploration of two communities, one urban (Philadelphia, PA) and one rural (Region 5, MN), exemplifies how comprehensive sustainability plans can bolster food systems, with leadership and strong engagement of public health departments that connect planners to underserved communities and provide the capacity to complete the work. Further, development of a comprehensive plan with a collaborative effort from public health and planning has the potential to impact the wellbeing of communities by influencing change beyond food. We observed this in Philadelphia and Region 5 where the integration of food facilitated more health-conscious planning related to the city's transportation system and economic development strategies, respectively.

Issues related to limited capacity to carry out food systems work, such as insufficient staffing, funding, and other resources, remains a challenge in both urban and rural communities. Cross-case results also reinforce how public health departments can help to overcome these barriers and constraints by pooling resources and helping to amplify food systems planning by establishing councils and salaried positions. In particular, the local health department in Philadelphia secured a multimillion dollar grant from the U.S. D epartment of Health and Human Services, and the local health department in Region 5 provided a dedicated source of funding through Minnesota's Statewide Health Improvement Program for food systems coordination, planning, and implementation. Furthermore, public health departments are well equipped to provide technical support and data collection, in the form of community needs assessments, eating patterns of residents, nutritionrelated health outcomes, and measurement of food access in communities, all of which are much needed data in monitoring and tracking progress in achieving plan goals. These findings are echoed in a prior study reporting on the food movement in New York City, in which public health professionals helped to amplify the health effects of the movement by facilitating conversations among stakeholders, providing empirical evidence and resources to augment policy change, evaluating the impact of the program, and offering technical and organizational support in community organizing and campaigning (Freudenberg, McD onough, \& Tsui, 2011).

Finally, as part of ongoing and future efforts, a key challenge in conjoining the planning and public health fields is to make certain that jointly developed strategies are not blind to the root and historical causes of food and health disparities, namely poverty, discrimination, and oppression. To succeed, planning and public policy processes must be fully democratic, as data from across the country suggest that lack of forethought in the design of policy and planning processes can exclude the very populations planners and public health advocates aim to serve (Clark et al., 2017). It is essential for planners and public health practitioners to work in partnership with local leaders and community members, particularly those who are socially marginalized, so food systems policy and programs meet the unique needs of communities. Leveraging a long history of food advocacy work in Philadelphia, and the R5DC inclusive civic engagement model, are prime examples of the ways in which local knowledge may be uplifted to achieve shared goals for an equitable, healthy, and sustainable food system.

\section{Conclusions}

The historic ties between the fields of planning and public health have been re-energized in recent decades by the need to address increasing health disparities in diet-related diseases, such as obesity and diabetes. We have learned that public health departments play a key role as liaisons in strengthening food systems, and the work of planners is 
reinforced by addressing the food system in a holistic manner, from policy to human health. This study documented how planners and public health practitioners have worked together to achieve more healthy, equitable, and sustainable communities through the development and implementation of comprehensive plans, in particular. A collaborative, interagency approach across public health and planning agencies is more likely to address placebased food inequities experienced by people, as was the case in Philadelphia, PA, and Region 5, $\mathrm{MN}$. This approach is especially promising in rural communities, where public health departments are more likely to have greater reach and influence than planning departments. Moving forward, such a collaborative approach, while essential, cannot stop with public health agencies. The public health and planning fields together can be further strengthened by connecting food systems to other functional systems, such as transportation, housing, economic development, and the environment. Further, to fully address the deepest inequities experienced by communities, inclusion is critical in public health and planning processes in order to lift up community-engaged solutions and advance meaningful change.

\section{Acknowledgements}

The authors thank the team at the University at Buffalo Food Systems Lab, the American Planning Association, and American Farmland Trust for their support.

\section{References}

American Planning Association. (2007). Policy guide on community and regional food planning. Chicago: American Planning Association. Retrieved from https:// www.planning.org/ policy/ guides/ adopted/ food.htm

Botchwey, N. D., Falkenstein, R., Levin, J., Fisher, T., \& Trowbridge, M. (2015). The built environment and actual causes of death: Promoting an ecological approach to planning and public health. Journal of Planning L iterature, 30(3), 261-281. https:/ / doi.org/ 10.1177/ 0885412214561337

Bridle-Fitzpatrick, S. (2015). Food deserts or food swamps? A mixed-methods study of local food environments in a Mexican city. Social Science \& M edicine, 142, 202-213. https:/ / doi.org/ 10.1016/ j.socscimed.2015.08.010

Caspi, C. E., Sorensen, G., Subramanian, S. V., \& Kawachi, I. (2012). The local food environment and diet: A systematic review. H ealth \& Plaœ, 18(5), 1172-1187. https:/ doi.org/ 10.1016/ j.healthplace.2012.05.006

Clark, J. K., Freedgood, J., Irish, A., Hodgson, K., \& Raja, S. (2017). Fail to include, plan to exclude: Reflections on local governments' readiness for building equitable community food systems. Built E nvironment, 43(3), 315-327. https:// doi.org/ 10.2148/ benv.43.3.315

Clifton, K. J. (2004). Mobility strategies and food shopping for low-income families: A case study. Journal of Planning E ducation and Research, 23(4), 402-413. https:// doi.org/ 10.1177/ 0739456X 04264919

Cobb, L. K., Anderson, C. A. M., Appel, L., Jones-Smith, J., Bilal, U., Gittelsohn, J., \& Franco, M. (2015). Baltimore City stores increased the availability of healthy food after WIC policy change. H ealth A ffairs, 34(11), 1849-1857. https:// doi.org/ 10.1377/ hlthaff.2015.0632

Connell, D. J., Bryant, C. R., Caldwell, W. J., Churchyard, A., Cameron, G., Johnston, T., . . Marois, C. (2013). Food sovereignty and agricultural land use planning: The need to integrate public priorities across jurisdictions. Journal of A griculture, F ood Systems, and Community D evelopment, 3(4), 117-124. https:// doi.org/ 10.5304/ jafscd.2013.034.011

Dubowitz, T., Zenk, S. N., G hosh-D astidar, B., Cohen, D. A., Beckman, R., Hunter, G., . . Collins, R. L. (2015). Healthy food access for urban food desert residents: Examination of the food environment, food purchasing practices, diet and BMI. Public H ealth N utrition, 18(12), 2220-2230. https:/ / doi.org/ 10.1017/ S1368980014002742

Epstein, L. H., Raja, S., Gold, S. S., Paluch, R. A., Pak, Y., \& Roemmich, J. N. (2006). Reducing sedentary behavior: The relationship between park area and the physical activity of youth. Psychological Scienœe, 17(8), 654-659. https:// doi.org/ 10.1111/j.1467-9280.2006.01761.x

Epstein, L. H., Raja, S., Oluyomi D aniel, T., Paluch, R. A., Wilfley, D. E., Saelens, B. E., \& Roemmich, J. N. (2012). The built environment moderates effects of family- based childhood obesity treatment over 2 years. A nnals of Behavioral M ediane, 44(2), 248-258. https:/ / doi.org/ 10.1007/ s12160-012-9383-4 
Journal of Agriculture, Food Systems, and Community Development

ISSN: 2152-0801 online

https:/ / www.foodsystemsjournal.org

Frank, L. D ., Andresen, M. A., \& Schmid, T. L. (2004). O besity relationships with community design, physical activity, and time spent in cars. A merican Journal of Preventive M edicine, 27(2), 87-96. https:// doi.org/ 10.1016/ j.amepre.2004.04.011

Frank, L. D., Sallis, J. F., Conway, T. L., Chapman, J. E., Saelens, B. E., \& Bachman, W. (2006). Many pathways from land use to health: Associations between neighborhood walkability and active transportation, body mass index, and air quality. Journal of the A merican Planning A ssociation, 72(1), 75- 87. https:/ / doi.org/ 10.1080/ 01944360608976725

Freudenberg, N., McD onough, J., \& T sui, E. (2011). Can a food justice movement improve nutrition and health? A case study of the emerging food movement in New Y ork City. Journal of U rban H ealth, 88(4), 623-636.

https:// doi.org/ 10.1007/ s11524-011-9598-x

Giles-Corti, B., Vernez-Moudon, A., Reis, R., Turrell, G., D annenberg, A. L., Badland, H., . . O O wen, N. (2016). City planning and population health: A global challenge. The L anœt, 388(10062), 2912-2924. https:/ / doi.org/ 10.1016/ s0140-6736(16)30066-6

Hodgson, K. (2012). Planning for food acess and community-based food system: A national scan and evaluation of local comprehensive and sustainability plans. Chicago: A merican Planning Association. Retrieved from https:// www.planning.org/ research/ foodaccess/

Jackson, R. J., Dannenberg, A. L., \& Frumkin, H. (2013). Health and the built environment: 10 years after. A merican Journal of Public H ealth, 103(9), 1542-1544. https:/ / doi.org/ 10.2105/ AJPH.2013.301482

Jennings, A., Welch, A., Jones, A. P., Harrison, F., Bentham, G ., van Sluijs, E. M. F., . . Cassidy, A. (2011). Local food outlets, weight status, and dietary intake: Associations in children aged 9-10 years. A merican Journal of Preventive M edicine, 40(4), 405-410. https:// doi.org/ 10.1016/ j.amepre.2010.12.014

Kirkpatrick, S. I., D odd, K. W., Reedy, J., \& K rebs-Smith, S. M. (2012). Income and race/ ethnicity are associated with adherence to food-based dietary guidance among US adults and children. Journal of the A cademy of $\mathrm{N}$ utrition and D ietetics, 112(5), 624-635.e6. https:/ / doi.org/ 10.1016/j.jand.2011.11.012

Koohsari, M. J., Sugiyama, T., Lamb, K. E., Villanueva, K., \& O wen, N. (2014). Street connectivity and walking for transport: Role of neighborhood destinations. Preventive M ediane, 66, 118-122. https:/ / doi.org/ 10.1016/ j.ypmed.2014.06.019

Lopez, R. P. (2009). Public health, the APHA, and urban renewal. A merican Journal of Public H ealth, 99(9), 1603-1611. https:/ / doi.org/ 10.2105/ AJPH.2008.150136

Luke, A., \& Cooper, R. S. (2013). Authors' response to commentaries on 'Physical activity does not influence obesity risk.' International Journal of E pidemiology, 42(6), 1848-1851. https:// doi.org/ 10.1093/ ije/ dyt171

Morgan, K. (2009). Feeding the city: The challenge of urban food planning. International Planning Studies, 14(4), 341-348. https:// doi.org/ 10.1080/ 13563471003642852

O gden, C. L., Carroll, M. D., Kit, B. K., \& Flegal, K. M. (2014). Prevalence of childhood and adult obesity in the United States, 2011-2012. JA M A , 311(8), 806-814. https:/ / doi.org/ 10.1001/ jama.2014.732

O gden, C. L., Carroll, M. D ., Lawman, H. G., Fryar, C. D., Kruszon-Moran, D ., Kit, B. K., \& Flegal, K. M. (2016). Trends in obesity prevalence among children and adolescents in the United States, 1988-1994 through 2013-2014. JA MA , 315(21), 2292-2299. https:/ / doi.org/ 10.1001/ jama.2016.6361

O wen, N., Humpel, N., Leslie, E., Bauman, A., \& Sallis, J. F. (2004). Understanding environmental influences on walking: Review and research agenda. A merican Journal of Preventive M edicine, 27(1), 67-76. https:// doi.org/ 10.1016/ j.amepre.2004.03.006

Peterson, J. A. (1979). The impact of sanitary reform upon A merican urban planning, 1840-1890. Journal of Social H istory, 13(1), 83-103. https:/ / doi.org/ 10.1353/ jsh/ 13.1.83

Philadelphia D epartment of Public Health. (2015). 2015 C ommunity H ealth A ssessment (CH A ): Philadelphia, PA . Retrieved from http:/ / www.phila.gov/ health/pdfs/ CommunityHealthAssessment2015.pdf

Pothukuchi, K. (2009). Community and regional food planning: Building institutional support in the United States. International Planning Studies, 14(4), 349-367. https:// doi.org/ 10.1080/ 13563471003642902

Pothukuchi, K., \& Kaufman, J. L. (2000). The food system: A stranger to the planning field. Journal of the A merican Planning A ssociation, 66(2), 113-124. https:/ / doi.org/ 10.1080/ 01944360008976093 
Raja, S., Born, B., \& Kozlowski Russell, J. (2008). A planners guide to community and regional food planning: Transforming food environment, facilitating healthy eating (Report No. 554). Retrieved from https:// www.planning.org/ publications/ report/ 9026878/

Raja, S., Raj, S., \& Roberts, B. (2017). The US experience in planning for community food systems: An era of advocacy, awareness, and (some) learning. In I. Knezevic, A. Blay-Palmer, C. Z. Levkoe, P. Mount, \& E. Nelson (Eds.), N ourishing communities: From fractured food systems to transformative pathways (pp. 59-74). Cham, Switzerland: Springer International.

Raja, S., \& Whittaker, J. (2018). Community food infrastructure: A vital consideration for planning healthy communities. In T. Beatley, C. Jones, \& R. Rainey (Eds.), H ealthy environments, healing spaces: Practios and directions in health, planning, and design (pp. 207-230). Charlottesville: University of Virginia Press.

Raja, S., Whittaker, J., Hall, E., Hodgson, K., \& Leccese, L. (2018). Growing food connections through planning: Lessons from the United States. In Y. Cabannes, \& C. Marocchino (Eds.), Integrating food into urban planning (pp. 135154. London: University College London Press and Food and Agricultural O rganization of the United Nations.

Raja, S., Y in, L., Roemmich, J., Ma, C., Epstein, L., Yadav, P., \& Ticoalu, A. B. (2010). Food environment, built environment, and women's BMI: Evidence from Erie County, New York. Journal of Planning E ducation and Research, 29(4), 444-460. https:// doi.org/ 10.1177/ 0739456X 10367804

Region Five D evelopment Commission. (2012). C reating a resilient region: The C entral M innesota Sustainable D evelopment Plan. Retrieved from http:/ / www.resilientregion.org/ plan/

Roemmich, J. N., Epstein, L. H., Raja, S., \& Y in, L. (2007). The neighbourhood and home environments: D isparate relationships with physical activity and sedentary behaviors in youth. A nnals of Behavioral M edicine, 33(1), 29-38. https:/ / doi.org/ 10.1207/ s15324796abm3301_ 4

Roemmich, J. N., Epstein, L. H., Raja, S., Yin, L., Robinson, J., \& Winiewicz, D . (2006). Association of access to parks and recreational facilities with the physical activity of young children. Preventive M edicine, 43(6), 437-441. http:// doi.org/ 10.1016/ j.ypmed.2006.07.007

Rosenbloom, A. L., Joe, J. R., Young, R. S., \& Winter, W. E. (1999). Emerging epidemic of type 2 diabetes in youth. D iabetes Care, 22(2), 345-354. https:// doi.org/ 10.2337/ diacare.22.2.345

Rosenzweig, C., Iglesias, A., Yang, X. B., Epstein, P. R., \& Chivian, E. (2001). Climate change and extreme weather events: Implications for food production, plant diseases, and pests. G lobal Change \& $\mathrm{H}$ uman $\mathrm{H}$ ealth, 2(2), 90-104. https:/ / doi.org/ 10.1023/ A:1015086831467

Rummo, P. E., Meyer, K. A., Boone-Heinonen, J., Jacobs, D. R., Kiefe, C. I., Lewis, C. E., . . G Gordon-Larsen, P. (2015). Neighborhood availability of convenience stores and diet quality: Findings from 20 years of follow-up in the Coronary Artery Risk D evelopment in Young Adults study. A merican Journal of Public H ealth, 105(5), e65-e73. https:// doi.org/ 10.2105/ Ajph.2014.302435

Sacks, G., Veerman, J. L., Moodie, M., \& Swinburn, B. (2011). 'Traffic-light' nutrition labelling and 'junk-food' tax: A modelled comparison of cost-effectiveness for obesity prevention. International Journal of 0 besity, 35, 1001-1009. https:/ / doi.org/ 10.1038/ ijo.2010.228

Sijtsma, F. P. C., Meyer, K. A., Steffen, L. M., Shikany, J. M., Van Horn, L., Harnack, L., . . Jacobs, D. R., Jr. (2012). Longitudinal trends in diet and effects of sex, race, and education on dietary quality score change: the Coronary Artery Risk D evelopment in Young Adults study. A merican Journal of Clinical N utrition, 95(3), 580-586. https:// doi.org/ 10.3945/ ajcn.111.020719

Sloane, D . C. (2006). Longer view: From congestion to sprawl: Planning and health in historical context. Journal of the A merican Planning A ssociation, 72(1), 10-18. https:/ / doi.org/ 10.1080/ 01944360608976720

Stokols, D . (1996). Translating social ecological theory into guidelines for community health promotion. A merican Journal of $\mathrm{H}$ ealth Promotion, 10(4), 282-298. https:/ / doi.org/ 10.4278/ 0890-1171-10.4.282

Story, M., Kaphingst, K. M., Robinson-O 'Brien, R., \& Glanz, K. (2008). Creating healthy food and eating environments: Policy and environmental approaches. A nnual Review of Public $\mathrm{H}$ ealth, 29, 253-272. https:// doi.org/ 10.1146/ annurev.publhealth.29.020907.090926 
Tabrizi, S. H., Segovia-Siapco, G., Burkholder, N. M., \& Sabate, J. (2014). Comparison of food intake patterns of adolescents with USD A My Plate D ietary Guidelines. FA SE B Journal, 28(1). Retrieved from https:// www.fasebj.org/ doi/ abs/ 10.1096/ fasebj.28.1 supplement.1024.15

Thorndike, A. N., Riis, J., Sonnenberg, L. M., \& Levy, D . E. (2014). Traffic-light labels and choice architecture: Promoting healthy food choices. A merican Journal of Preventive M edicine, 46(2), 143-149. https:/ / doi.org/ 10.1016/ j.amepre.2013.10.002

U.S. Burden of D isease Collaborators. (2013). The state of US health, 1990-2010: Burden of diseases, injuries, and risk factors. JA MA , 310(6), 591-608. https:/ / doi.org/ 10.1001/ jama.2013.13805

Vitiello, D ., \& Wolf-Powers, L. (2014). Growing food to grow cities? The potential of agriculture foreconomic and community development in the urban United States. C ommunity D evelopment Journal, 49(4), 508-523. https:// doi.org/ 10.1093/ cdj/ bst087

Ward, B. W., Schiller, J. S., \& G oodman, R. A. (2014). Multiple chronic conditions among US adults: A 2012 update. Preventing Chronic D isease, 11, 130389. https:/ / doi.org/ 10.5888/ pcd11.130389

Whitehead, M., \& D ahlgren, G . (1991). What can be done about inequalities in health? L ancet, 338 (8774), 1059-1063. https:// doi.org/ 10.1016/ 0140-6736(91)91911-D 